\title{
MIDAS
}

Museus e estudos interdisciplinares

$6 \mid 2016$

Dossier temático: "Museus, discurso e poder"

\section{La museización del patrimonio memorial transfronterizo: el caso del exilio republicano y sus espacios}

Museification of the cross-border memorial heritage: the Republican exile case and its sites

David González Vázquez y Jordi Font Agulló

\section{OpenEdition}

Journals

Edición electrónica

URL: http://journals.openedition.org/midas/1030

DOI: $10.4000 /$ midas. 1030

ISSN: 2182-9543

Editor.

Alice Semedo, Paulo Simões Rodrigues, Pedro Casaleiro, Raquel Henriques da Silva, Ana Carvalho

\section{Referencia electrónica}

David González Vázquez y Jordi Font Agulló, « La museización del patrimonio memorial

transfronterizo: el caso del exilio republicano y sus espacios », MIDAS [En línea], 6 | 2016, Puesto en línea el 24 marzo 2016, consultado el 20 abril 2019. URL : http://journals.openedition.org/midas/1030 ; DOI : 10.4000/midas. 1030

Este documento fue generado automáticamente el 20 abril 2019.

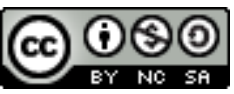

Midas is licensed under a Creative Commons Attribution-NonCommercial-ShareAlike 3.0 International License 


\section{La museización del patrimonio memorial transfronterizo: el caso del exilio republicano y sus espacios}

Museification of the cross-border memorial heritage: the Republican exile case and its sites

David González Vázquez y Jordi Font Agulló

\section{NOTA DEL EDITOR}

Artigo recebido a 31.03.2015

Aprovado para publicação a 12.12.2015

\section{Introducción: la frontera ante el hecho histórico}

1 Los espacios transfronterizos de la Europa occidental pueden ser catalogados como aquellos lugares donde la progresiva disolución de las funciones convencionales de las fronteras ha ido desarrollando un determinado paisaje que, independientemente de la efectividad real de dicha desaparición con respecto a muchos aspectos concretos, reivindica los vínculos existentes a ambos lados. La historia de esos lugares está plagada de hechos que le suponen atribuirse el epíteto de común, pues pese a haber formado parte de realidades nacionales o estatales diferentes, han compartido el desarrollo y evolución de muchos de aquellos hechos.

2 La Europa de la Unión, tras eliminar las fronteras internas entre todos los países firmantes del tratado de Schengen, vigente desde 1995, ha desarrollado dentro de su marco institucional unas zonas, las euroregiones, destinadas a potenciar aquellos puntos comunes derivados de la antigua relación entre entes estatales nacionales diferentes. El 
caso al que nos referimos estaría representado por la Euroregión Pirineos-Mediterraneo, y más en concreto la subárea del Espacio Catalán Transfronterizo. La zona de la hipotética antigua frontera francoespañola en su parte oriental, de hecho, puede considerarse como una de las más impermeables de la UE (Pujol 2008), es decir, que persisten en ella numerosas reminiscencias tanto de los hábitos de control policial como de arraigados comportamientos socioculturales que ahondan en la división del territorio. Pese a ello, gracias a esta nueva situación que podríamos denominar de postfrontera, ha sido posible la puesta en valor de muchos elementos comunes.

3 La frontera, entendida en un sentido amplio, representa un lugar eminentemente singular en la historia, ya que permite vivenciar tanto la alegría del reencuentro como la tristeza de los conflictos y sus recuerdos (Foucher 1991). Está destinada, en tanto que elemento histórico, a sufrir el devenir de los tiempos y a ver modificada su ubicación, tamaño y magnitud social (Schlögel 2007). Aun moviéndose o desapareciendo a nivel formal, como en el actual contexto de la UE, la zona de frontera evoca frecuentemente aquellos hechos excepcionales de gran impacto emocional (Camiade 2010) que han calado muy hondo en el imaginario colectivo de las gentes del lugar. Así, un territorio transfronterizo, al atestiguar dichos episodios de evocación emotiva colectiva, es el terreno ideal para desarrollar un paisaje de memoria, esquema que encontramos perfectamente plasmado en la frontera franco-belga y sus espacios de memoria de la Primera y Segunda Guerra Mundial (Verkindt y Blanc 2013).

4 La frontera se percibe desde una perspectiva clara de ambigüedad, donde un mismo lugar puede representar el puente para el encuentro con el otro, así como también puede ser una barrera para su rechazo (Magris 2001). Tal fue la situación de la frontera francoespañola durante la Segunda Guerra Mundial. Consolidado el éxodo masivo de republicanos hacia la frontera norte, los Pirineos sirvieron como vía de escape a muchos judíos, así como a jóvenes franceses que huían del régimen de Vichy para incorporarse a las filas de la Francia libre, o a aviadores aliados abatidos que terciaban para llegar a los consulados o embajadas de sus países en la España franquista. En el caso de la población judía, atravesar la cordillera pirenaica podía suponer escapar de la persecución nazi o, por el contrario, la consolidación del drama personal en forma de encarcelamiento y posterior deportación (Calvet 2008).

5 La historia y la memoria nunca han entendido de fronteras, aunque para el caso del exilio republicano español, así como de los efectos colaterales de la Segunda Guerra Mundial en la zona, su existencia ha resultado imprescindible para entender el proceso posterior de forjamiento de una memoria trágica ligada a unos hechos históricos concretos. Entre los últimos días de enero y los primeros de febrero del año 1939 se vivió uno de los episodios de desplazamientos masivos de población más importantes del siglo XX. Alrededor de unas 475000 personas dejaron todo atrás y se dirigieron a la frontera pirenaica huyendo de España a Francia. Cataluña, territorio donde la experiencia revolucionaria durante la Guerra Civil de 1936-1939 se desarrolló profundamente, había caído en manos franquistas y la represión se estimaba brutal. Por ello muchas personas, mujeres, niños y ancianos incluidos, decidieron emprender el camino al exilio sin importarles mucho el futuro inmediato. El gobierno francés, de signo conservador por aquel entonces, decidió emplazar a todo el contingente de refugiados en improvisados campos de concentración, los cuales irían consolidándose en los meses y años posteriores a su llegada. De ahí solo saldrían para volver a España, para huir a un tercer país si conseguían un visado, o para incorporarse al ejército francés o a las Compañías de Trabajadores Extranjeros en el 
contexto de la ya iniciada Segunda Guerra Mundial. La huella de estos trágicos sucesos quedó marcada fuertemente en el territorio, aunque su recuperación memorial a nivel colectivo, como en el resto de memorias traumáticas europeas, no se empezó a producir hasta los últimos años de la década de 1970. La Retirada es el nombre con el cual se conoce en Francia, y desde finales de los años de 1990 del siglo pasado se han emprendido acciones de dignificación memorial a lo largo de la región rosellonesa (Departamento de los Pirineos Orientales), que han culminado con las diferentes iniciativas museísticas existentes en la actualidad.

6 Este pasado trágico representa un importante patrimonio histórico y memorial cuya divulgación se entiende como un deber de memoria. Ejecutado mediante la creación de espacios memoriales museizados alrededor del territorio, debe colaborar con la reflexión acerca de la trágica historia de la Europa del siglo XX, para así contribuir a la consolidación de una sociedad garante de libertad y derechos humanos. Así, el espacio transfronterizo francoespañol, en su parte más oriental, dispone del potencial suficiente como para abordar la museización de su historia reciente de manera que los más diversos e importantes temas sean tratados de forma fidedigna. Fascismo, revolución, Guerra Civil española y sus refugiados, democracia, exilio republicano, resistencia nacional y cultural catalana, campos de internamiento, condiciones de vida, derechos humanos, Segunda Guerra Mundial, refugiados del nazismo, deportación y genocidio del pueblo judío, oposición contra el franquismo, pasos clandestinos de frontera y redes de evasión, expresión artística en el exilio, etc., conforman todo un universo de interesantes temáticas que están presentes en las diferentes experiencias museizadoras existentes en el territorio.

\section{La museización del patrimonio memorial}

7 En la categoría de patrimonio memorial entran todos aquellos lugares con una significación histórica y de memoria concretos, y que comúnmente nos remiten a un pasado trágico. El origen del tratamiento exhaustivo del estudio de dichos lugares se encuentra en la recurrencia de estudios sobre el Holocausto en los años 80 (Huyssen 2002; Lalieu 2003). La potencia de los lugares de memoria como elemento evocador del trauma, así como de posibles consecuencias históricas del mismo como el olvido y la vergüenza colectivos, es tal, que toda una sociedad en su conjunto es capaz de olvidar los hechos ligados a la memoria de dichos lugares. Como caso paradigmático, donde la amnesia colectiva se impuso a todos los niveles de la sociedad, tenemos el ejemplo de la Alemania de postguerra, donde millones de personas hicieron tabula rasa y obviaron el terror vivido y provocado por el nazismo. Ha hecho falta llegar a las postrimerías del siglo XX para que, fruto de la asimilación de dicho pasado, se haya comenzado un proceso de patrimonialización de los espacios de memoria ligados a la Segunda Guerra Mundial y al Holocausto. Lugares como antiguos campos de concentración, no solo en Alemania sino en otras partes de Europa, han sido museizados y muestran, en clave pedagógica, las barbaridades allí cometidas. Ejemplos de referencia en este ámbito son los memoriales ubicados en los antiguos campos de Sachsenhausen-Berlín (Alemania), Mauthausen (Austria) o Auschwitz (Polonia).

8 Pero años antes, en un contexto anterior al de la recuperación memorial de Europa occidental en su conjunto, ya encontramos la primera gran referencia de museo memorial. Israel, tras su consolidación como estado en tierras palestinas, promueve la 
creación de un gran equipamiento museístico encargado de conmemorar y difundir la memoria de los 6 millones de judíos exterminados por la Alemania nazi. El Museo Memorial del Holocausto de Yad Vashem abre sus puertas en 1953, y desde entonces ha sido referencia a nivel mundial. En 2005 se han acometido las obras de renovación que, ante la proliferación de equipamientos museísticos de carácter similar, han hecho posible que siga siendo hoy día el equipamiento museístico más reseñable en su categoría (Santacana y Hernàndez 2011). Unas cifras de 2 millones de visitantes anuales de manera regular y sus políticas de difusión pedagógica, con la participación en numerosos programas alrededor del mundo, así lo confirman.

9 Pero si hay un lugar donde la puesta en valor del patrimonio memorial ha supuesto un auténtico hito cultural, a la par que económico, es Francia. El país galo ha sido pionero en la creación de una estructura en red encargada de la difusión de una tipología de turismo muy concreta, el tourisme de mémoire, donde mediante la señalización y museización de sus espacios de memoria, han dado a estos un valor patrimonial de máxima importancia (González 2014). En palabras de Cavaignac y Deperne (2003, 14), esta nueva tipología representa «una práctica turística que incita al público a explorar los elementos patrimoniales puestos en valor, para así extraer todo el enriquecimiento cívico y cultural que nos proporciona la referencia al pasado». La mencionada red, denominada chemins de mémoire, nació fruto del trabajo conjunto entre los ministerios de defensa y de turismo, y catalogó sus diferentes espacios miembros dentro de cuatro categorías: la fortificación (siglo XVI-XIX), guerra franco-prusiana (1870-71) y las dos guerras mundiales. Sin embargo, tras más de una década de recorrido, puede afirmarse que el grueso de espacios de la red corresponde a las dos guerras mundiales, así como también a uno de los efectos colaterales de la Segunda Guerra Mundial, el Holocausto (Bouliou 2013).

Este contexto francés de fomento de una práctica turística ligada a sus espacios de memoria, viene dado por un bagaje anterior de varias décadas en lo referente a la puesta en valor del patrimonio memorial. Según el análisis de Atout France (Mantei 2012), la agencia nacional de turismo de Francia, el 19\% de los lugares patrimoniales de memoria puestos en valor y, por tanto, visitables, ya existían antes de 1980. Este dato es clave para comprender como una vez entrado el siglo XXI, con el crecimiento y la multiplicación de los mismos, sean considerados como pieza fundamental de la oferta cultural de muchas regiones. De la misma forma, a nivel teórico han sido numerosas las aportaciones al respecto de la función, los usos y el contenido del turismo de memoria. Sus objetivos principales son la educación cívica y el desarrollo territorial, sin olvidar la gran oportunidad que supone la reconversión a nuevos usos del ingente patrimonio militar en desuso (Da Silva y Bougon 2013), y teniendo siempre presente que hablamos de una práctica pedagógica. Con ella, se trata de despertar la conciencia histórica del visitante, entendiendo el epíteto histórico no como el acto de recordar, sino como algo mucho más profundo. Se trata de, mediante el recuerdo, reconocer y aceptar nuestro pasado, por muy duro que sea (Urbain 2003). Una buena estrategia museográfica, así como la utilización efectiva de las herramientas de difusión disponibles, deben hacer posible la divulgación del discurso pedagógico elaborado para la puesta en valor del espacio. En palabras de Lalieu $(2003,29)$, «se trata de preservar un espacio desarrollando un recorrido de visita racional, y creando elementos museográficos de sensibilización y conocimiento».

11 Francia es pues, tal y como atestigua Guixé $(2008,223)$, el auténtico referente a nivel mundial: «es el país que ofrece una red de museos y memoriales más densa... allí se ha generado un amplio debate sobre la constante renovación de contenidos, señalización y 
banalización o no de los espacios memoriales a través del turismo». El impacto de la puesta en valor patrimonial en clave museística es incontestable. Las cifras del anteriormente mencionado estudio de Atout France (Mantei 2012), hablan de más de 6 millones de visitantes el año 2010. Si se tiene en cuenta que los espacios analizados en dicho estudio suponen únicamente el $20 \%$ del total de lugares dedicados al turismo memorial en Francia, podemos hacernos una idea de la relevancia de las cifras globales.

\section{Los espacios de memoria en Cataluña}

El contexto memorial al sur de los pirineos tiene unas características muy diferentes al del resto de la Europa occidental. En España, el principal proceso forjador de memoria colectiva fue la Guerra Civil (1936-1939), y el resultado de ésta, con la victoria de los militares rebeldes y la coalición conservadora que los apoyaba, impuso un cruel régimen totalitario durante aproximadamente cuatro décadas. A lo largo de ese tiempo, el paradigma memorial estaba destinado a la glorificación de los caídos por dios y por la patria, es decir, las víctimas pertenecientes al bando sublevado. Con el proceso de transición a la democracia, dicho paradigma cambió hacia posiciones de equidistancia, pasando de la gloria a los caídos del bando vencedor al silencio, al olvido, y a la catarsis colectiva donde se equiparaban las culpas entre los rebeldes golpistas y los defensores de la legalidad democrática. No ha sido hasta la entrada del actual siglo, gracias en gran parte al empuje de las asociaciones por la recuperación de la memoria histórica (Bernecker, Brinkmann y Muñoz-Aunión 2009), que se ha avanzado un paso más, y se ha situado el paradigma de la memoria colectiva en España en la actual fase de intento de reparación moral de todas las víctimas del franquismo, ya sea durante la guerra o bien durante la dictadura.

13 A propósito del empuje asociacionista, se llevaron a cabo unas tímidas medidas de implementación de políticas públicas de la memoria, que acabaron cristalizando con la promulgación de la Ley de Memoria Histórica (Ley 55/2007) para el conjunto del estado español, y la Llei del Memorial Democràtic (Llei 13/2007) para Cataluña. En el caso catalán - con un ley más precisa e incisiva -, nació además una institución creada expresamente para recuperar, conmemorar y fomentar la memoria democrática del país, el Memorial Democràtic. La instauración de dicha institución ha supuesto que la memoria democrática haya recibido la categoría de patrimonio, y por ende, la necesidad de ser transmitido a las futuras generaciones de ciudadanos (Vinyes 2009).

En el artículo número 3 de la mencionada Llei del Memorial Democràtic (Llei 13/2007, 45.175) se hace referencia a las ocho funciones que debe desarrollar la institución, entre las que destacamos la siguiente:

La difusión del patrimonio memorial democrático y de los espacios de memoria, con la creación de un fondo informativo integrado por un servicio de información documental, un portal informático, un banco de datos audiovisuales y bases de datos, y también con la organización de exposiciones.

Esta será la base a partir de la cual se empiece a trabajar en la valorización del patrimonio memorial democrático catalán, ligándolo asimismo a los espacios de memoria representativos del mismo. Así, en el año 2010 nace la Xarxa d'Espais de Memòria Democràtica de Catalunya (Ordre IRP/91/2010), cuya vocación es ser el nexo de unión entre todas aquellas administraciones locales que quieran poner en valor su patrimonio ligado a la memoria democrática. Sus objetivos generales pasan por recuperar, señalizar y 
difundir todo el patrimonio memorial democrático dentro del ámbito de actuación cronológico establecido entre los años 1931 y 1980. En lo referente a la categorización de los elementos que forman parte de la red, la orden legislativa de la creación de la misma dice lo siguiente:

La red de espacios de memoria incluirá territorios de memoria, centros expositivos de referencia, patrimonio recuperado in situ (trincheras, bunkers, espacios de duelo $\mathrm{y}$ fosas comunes, etc.), caminos de memoria (rutas del exilio, camino de la libertad, etc.), lugares y espacios de resistencia, archivos y centros de documentación, y monumentos memoriales. (Ordre IRP/91/2010, 14.651)

Además de quedar establecida una estructura jerárquica entre sedes, centros de referencia, y espacios a secas, se dictamina una división de los espacios pertenecientes a la red en cuatro grandes ámbitos temáticos: Segunda República, Guerra Civil, Frontera y exilio, y Lucha antifranquista y recuperación democrática.

\section{Espacios de frontera y exilio}

17 Así pues, en el marco de la Xarxa d'Espais de Memòria de Cataluña, existe una categoría de espacios dedicada a la frontera y el exilio. Evidentemente, los espacios enmarcados en este grupo se encuentran en las comarcas septentrionales de Cataluña por ser lugar fronterizo con Francia. El elemento principal que elabora un discurso histórico para estos espacios es el exilio republicano del año 1939, como así muestra la proliferación de elementos ligados a este hecho. Sin embargo, hay otro eje de referencia al respecto de la frontera, que estaría relacionado con los efectos colaterales de la Segunda Guerra Mundial en la zona. De esta manera, como ya se ha apuntado con anterioridad, encontramos espacios de memoria relacionados con la huida de judíos desde Francia a España con la esperanza de seguir con su viaje hasta un tercer país (en América o Palestina). Se trata de un episodio relativamente poco difundido $\mathrm{y}$, sin duda, la puesta en valor de sus espacios de memoria colabora crucialmente a la hora de incorporarlo a la agenda del estudio histórico. Asimismo, ponen de manifiesto la importancia del territorio catalán durante el transcurso de la Segunda Guerra Mundial como lugar de frontera. La supuesta neutralidad de la España franquista ante la contienda mundial queda muy en entredicho si se analiza el papel de sus fuerzas de seguridad y de la política llevada a cabo con respecto al tema de los judíos que huían del nazismo. Los memoriales existentes en Portbou (Alt EmpordàGirona), o la museización de la prisión de Sort (Pallars Sobirà-Lleida) atestiguan de cara al visitante estos hechos históricos.

\section{El exilio republicano: un patrimonio memorial transfronterizo}

18 Sin duda, la acción más importante para museizar el patrimonio memorial relacionado con el exilio republicano se llevó a cabo en febrero de 2008. En aquella fecha, después de la consecución de recursos y de un largo proceso de construcción y ejecución del proyecto, se inauguró el Museu Memorial de l'Exili (MUME) en La Jonquera. Con el empuje del ayuntamiento de dicho municipio, y con el sostén decisivo de fondos de la Unión Europea y de la Generalitat de Cataluña, se creó un consorcio para gestionar el equipamiento museístico. El MUME se convirtió en el eje de un territorio de memoria transfronterizo centrado en la puesta en valor de un pasado común a un lado y otro de la 
cadena montañosa. Dedicado a la divulgación del exilio republicano como acontecimiento histórico esencial en la configuración de la Cataluña contemporánea y a la preservación de su memoria, poco a poco desde el museo se fueron estableciendo lazos con proyectos memoriales impulsados tanto desde el marco institucional como desde de la sociedad civil de ambos lados de la frontera.

Ciertamente, la aparición del MUME ha tenido un efecto catalizador en esta área transfronteriza en cuanto a la recuperación de la memoria del exilio republicano se refiere. Se ha producido una simbiosis entre la apuesta institucional, que ha encabezado el MUME hasta este momento, y las iniciativas ya preexistentes, vinculadas a actos conmemorativos propulsados por asociaciones y ayuntamientos. Estos últimos, como veremos, también han ido jugando un papel muy notable en relación a la recuperación de espacios significativos, al trazado y señalización de rutas o a la recogida de testigos. Incluso, han dado un paso más allá y han creado pequeños centros de interpretación, como ha sido el caso de Elne, Argelès y Agullana.

Aunque sea brevemente, del MUME cabe destacar su exposición permanente. En concreto, el relato histórico - que empieza en los años de la II República española y acaba en el período de la transición a la democracia - se plasma mediante una museografía sobria que transmite la dureza de la experiencia del exilio y, además, invita al visitante a una reflexión ética no exenta de emotividad. Asimismo, otro aspecto relevante es que, desde un buen inicio, el eje del trabajo a desarrollar en el territorio inmediato ha partido de la idea de museo difuso (Alessandrone Perona 2005). Esto ha permitido la articulación de una serie de actividades que, capitaneadas por el Servicio Educativo del MUME, han contribuido a crear conciencia de red territorial. Itinerarios a pie por pasos fronterizos que fueron utilizados en el momento del Exilio de 1939, visitas guiadas a espacios que albergaron campos de concentración como Argelès, Saint Cyprien o Rivesaltes, desplazamientos hasta parajes donde son perceptibles vestigios de ese momento histórico como la Vajol o Elne, o a lugares que se asocian a personajes de gran notoriedad como Antonio Machado en Colliure, Pau Casals y Pompeu Fabra en Prades o el mismo Walter Benjamin en Portbou, configuran un paisaje de memoria que ha ido adquiriendo una fuerte personalidad. El MUME, al salir de los límites de sus paredes y tener una clara predisposición transfronteriza, ha colaborado a aunar y a hacer revivir lo que eran recuerdos dispersos y lugares casi olvidados. Y lo que ha sido más importante es que la apertura del museo ha confirmado que, junto al envite más reivindicativo de lo que se ha llamado la recuperación de la memoria histórica, existe también un verdadero patrimonio memorial e histórico por revalorizar y darle visibilidad. Este contexto favorable ha estimulado que algunos municipios, con el apoyo de administraciones regionales y fondos europeos, hayan considerado la posibilidad de museizar o conservar algunos espacios de memoria o, incluso, - tal como se ha indicado anteriormente - la creación exnovo de lo que podríamos denominar centros de interpretación. 


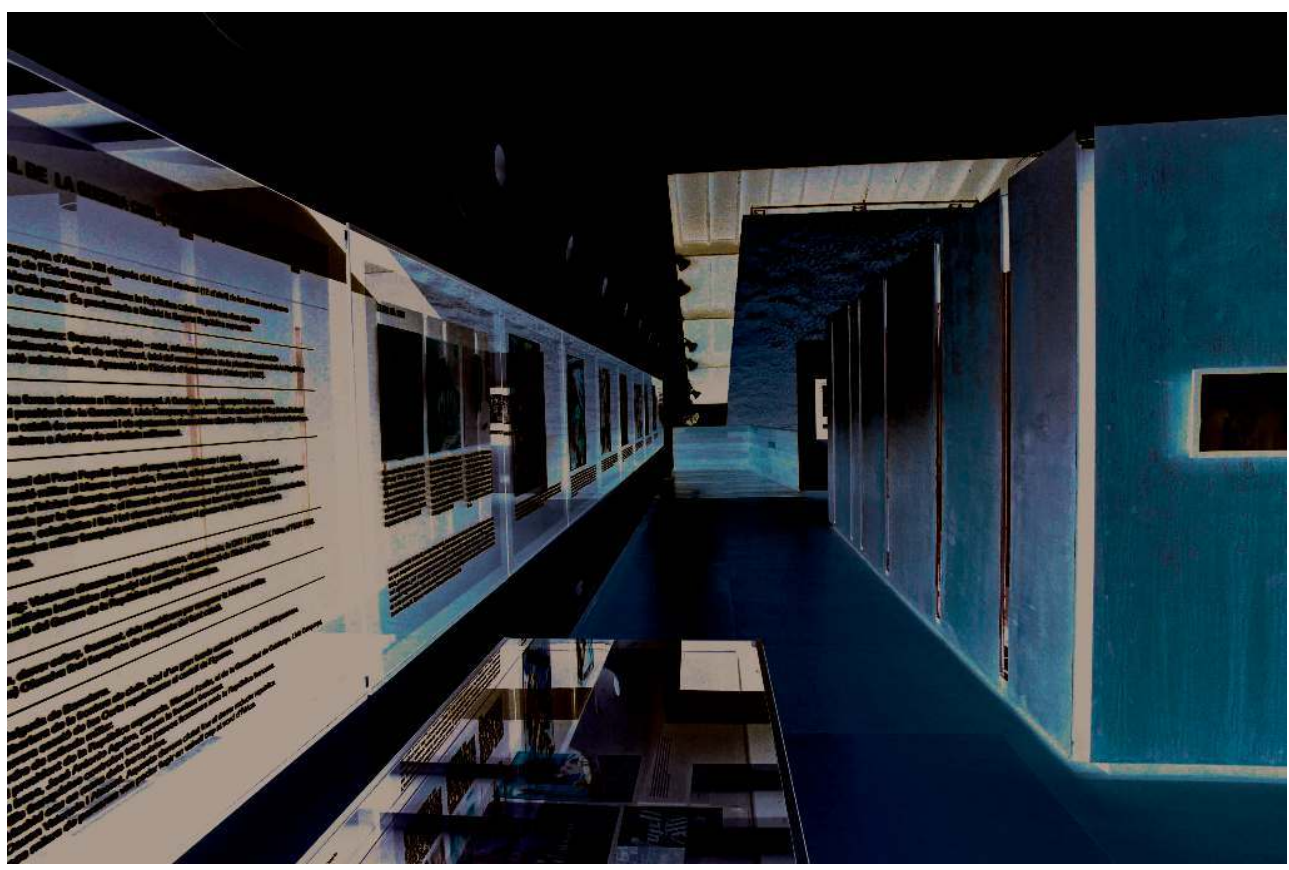

FIg. 1 - VISTA INTERIOR, MUSEU MEMORIAL DE L'EXILI, 2010

(c) MUME

21 A continuación, de manera sucinta, vamos a tratar de introducir algunos comentarios descriptivos y valorativos sobre algunas de esas iniciativas que centran sus esfuerzos en la recuperación de la memoria en torno al exilio republicano. El primer caso a tener en cuenta es el de Argelès-sur-mer. Como es sabido en el imaginario colectivo del Exilio republicano, Argelès no es sólo el nombre de una población costera del Rosellón donde se ubicó el primer campo de concentración para los refugiados que atravesaron la frontera en febrero de 1939. Es, sin duda, más allá de la realidad tangible de la existencia del recinto de internamiento para republicanos españoles, el vocablo que mejor encarna la humillación y el sufrimiento a que fueron sometidos esos refugiados por parte de las autoridades de la Francia republicana de la época. La arena de la playa, la falta de un mínimo cobijo ante las inclemencias climáticas, la ausencia de higiene, la promiscuidad y el amontonamiento, la muerte de los más debilitados, la separación entre hombres y mujeres, constituyen un recuerdo traumático que se ha transferido entre generaciones.

En este municipio, pese a que hoy en día el lugar que ocupó el campo es imperceptible pues se trata de una zona característicamente turística de sol y playa, el peso de la memoria del campo ha estado siempre presente. No obstante, no fue hasta casi a finales de los años 1990, coincidiendo con el 60. aniversario del Exilio republicano, que no se empezó a llevar a cabo una persistente política memorial. Nació en esa época la asociación Fils et Filles des Républicains Espagnols et Enfants de l'Exode (FFREEE) y poco después el mismo ayuntamiento de Argelès participó activamente como socio en la petición de una ayuda europea INTERREG para llevar a cabo el MUME en La Jonquera. La contrapartida era la apertura, en Argelès, de un centro de documentación sobre el campo de concentración. Casi una década después, el centro de documentación, situado en el Château de Valmy (Espace Jules Pam), se ha convertido también, desde febrero de 2014, en un centro de interpretación sobre ese lugar de internamiento de refugiados que lleva el nombre de "Mémorial du Camp d'Argelès". Concebido como un espacio monográfico sobre el campo de concentración, el visitante se adentra en una museografía moderna, 
con elementos audiovisuales y digitales, y objetos originales procedentes del campo, que se extiende en unos 150 metros cuadrados. Los precedentes históricos del conflicto español, la construcción del campo, la vida cotidiana y las diferentes fases en que estuvo operativo dicho recinto son los principales ítems que definen una pequeña pero rigurosa exposición.

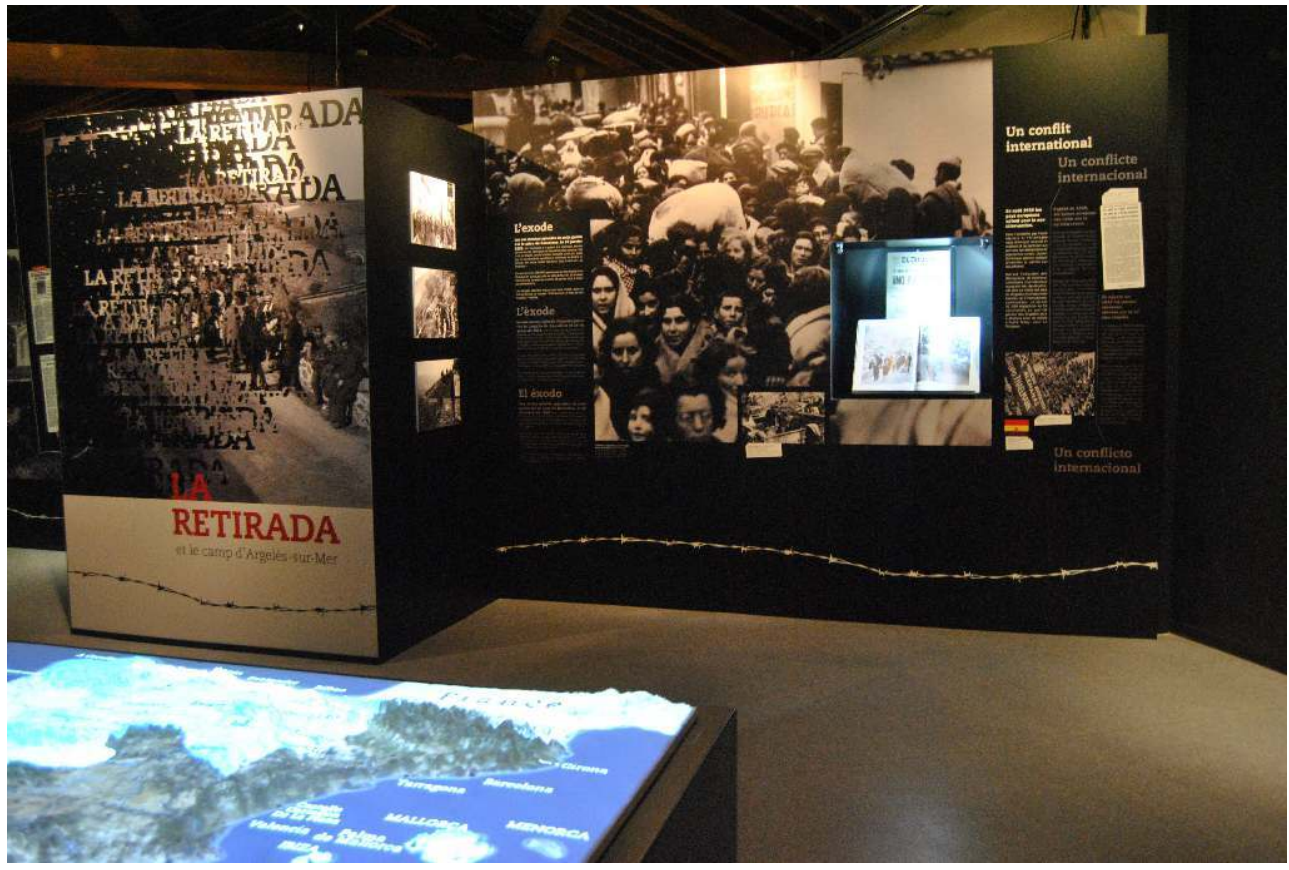

FIg. 2 - VISTA INTERIOR, MEMORIAL DU CAMP D'ARgELÈS, 2014

(C) MUME

23 La especificidad de Argelès, centrada en el universo concentracionario creado por una República francesa de 1938-1939 inmiscuida en una fase creciente de derechización, es una apuesta seria que se complementa muy bien con el discurso de tipo generalista que se proyecta desde el MUME. Algo parecido ocurre con otras dos importantes ya realidades museísticas. Una de ellas es la Maternidad de Elne. En este caso, el papel de las autoridades locales también fue decisivo. Después de años de olvido, a principios del presente siglo el ayuntamiento de Elne adquirió un palacete que entre 1939 y 1944 fue la maternidad del campo de concentración de Argelès, así como de otros campos circundantes. En ese lugar, gracias a la pericia y la dirección de una joven suiza, Elisabeth Eidenbenz, que trabajaba en la Cruz Roja suiza, funcionó durante casi cinco años un centro maternal donde nacieron alrededor de 600 niños, 400 de ellos hijos de refugiadas republicanas y el resto de refugiadas judías y gitanas que, en esa época, eran catalogadas por las autoridades francesas como población indésirable. La Maternidad de Elne, a diferencia de Argelès y del siguiente caso que comentaremos, Agullana, conserva el edificio-testimonio. Es un lugar histórico y un lugar de memoria potentísimo. Actualmente, con una mínima museografía - existe un proyecto museológico integral en perspectiva de desarrollarse -, la antigua Maternidad es uno de los espacios que recibe más visitas. Faro de luz en una Europa oscurecida por el nazismo y cuna de solidaridad humana en medio del desastre humanitario de los campos de las playas del Rosellón, ha adquirido actualmente casi el cariz de mito. El compromiso humanitario de Elisabeth Eidenbenz, el nacimiento de los niños y su salvación de los peligros epidémicos de los campos han otorgado a ese lugar una intensa dosis de emotividad. 


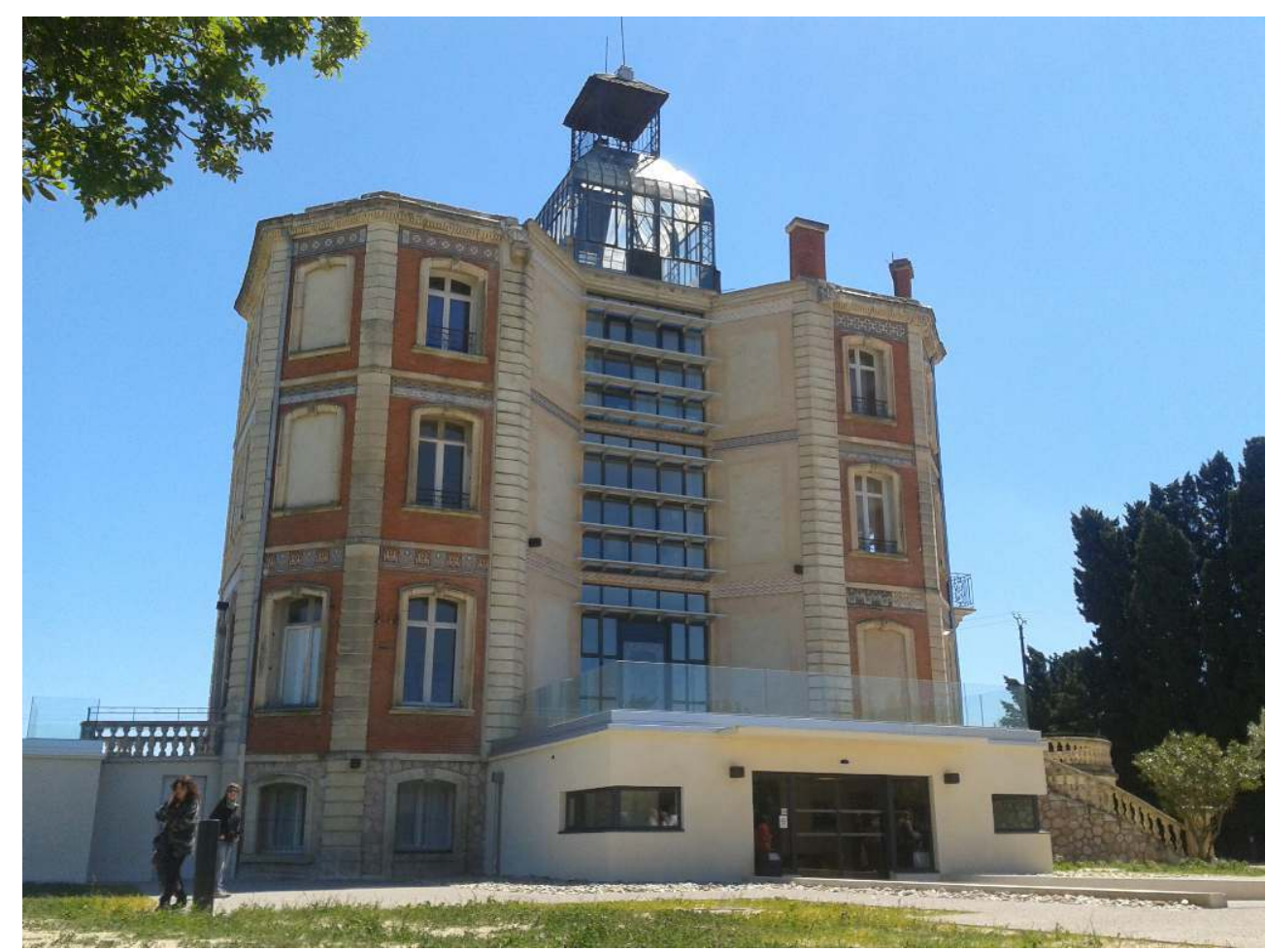

Fig. 3 - Edificio-TESTIMONIO, MATERNITAT d'ELNE, 2013

(C) MUME

El tratamiento de aspectos concretos en Argelès y Elna sin duda beneficia el devenir de la red memorial transfronteriza sobre el exilio republicano. En esta misma línea, recientemente se acaba de inaugurar un centro de interpretación en Agullana, municipio catalán situado a tres quilómetros de La Jonquera. En esta pequeña población catalana, en enero y principios de febrero de 1939, se concentraron representantes de gobiernos extranjeros aliados de la República española, las más dispares instituciones republicanas, desde secciones de ministerios a Estados mayores, así como delegaciones del gobierno vasco y del gobierno catalán. Este último, con su presidente Lluís Companys a la cabeza, se alojó en un caserío, el Mas Perxés, durante unos días antes de cruzar la frontera. Al lado de los políticos, también llegó un número importante de intelectuales, escritores, profesionales, etc. Seguramente, el grupo más relevante de la entonces recuperada cultura catalana. Todos ellos emprendieron el camino del exilio, suponiendo para la Cataluña ocupada por el franquismo una pérdida irreparable. Agullana, pues, simboliza esa última parada de una cultura ya casi en el exilio. Teniendo en cuenta toda esta simbología, el ayuntamiento actual de Agullana - una vez más la administración local decidió llevar a cabo, en compenetración con el MUME, un centro de interpretación dedicado a la cultura catalana en el exilio y a la cultura catalana que nació en el exilio. Este centro, con el nombre de "L'exili Cultural Català de 1939", propone un recorrido por el conjunto de las letras, el pensamiento y las ciencias catalanas en la difícil disyuntiva del exilio. El visitante se encuentra ante un alud de información que evoca la enorme producción de los actores del exilio cultural catalán: revistas históricas y literarias, novela, teatro, música, ciencia, medicina, enseñanza, arte, etc. Con una museografía escueta y un uso muy eficiente de los recursos audiovisuales, este pequeño centro contribuye a ofrecer una dimensión cultural del exilio que en el MUME no se acaba de explicitar ya que el discurso preeminente se circunscribe más en lo político y lo social. 


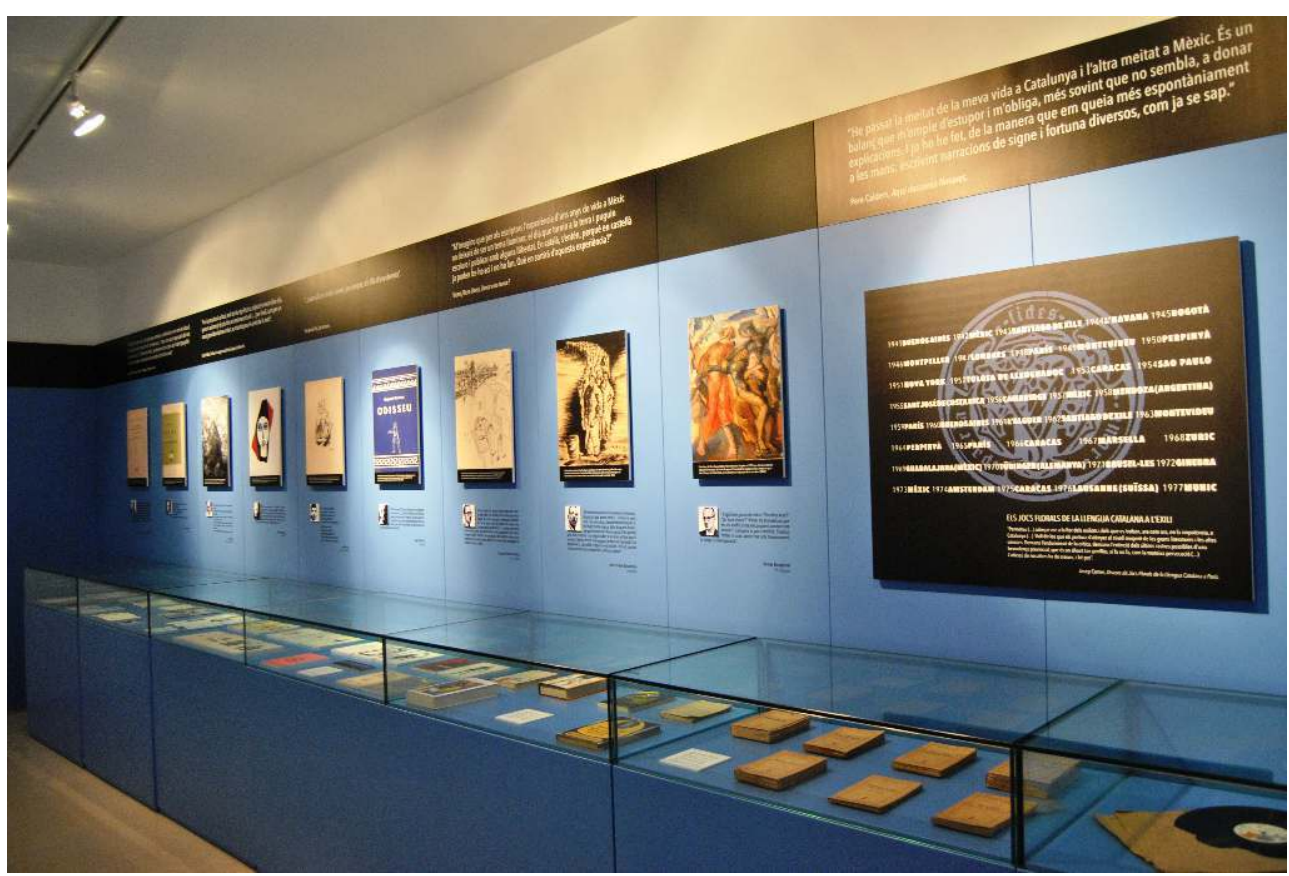

Fig. 4 - VistA INTERIOR. CENTRO DE INTERPRETACIÓN “'́EXILI CULTURAL CATALÀ DE 1939”, 2015 (C) MUME

Vamos a acabar este apartado haciendo un breve comentario a lo que, desde octubre de 2015, es un importante espacio de memoria museizado. Nos estamos refiriendo al Memorial del Campo de Rivesaltes. Con el apoyo de la administración estatal y regional francesa se ha hecho realidad un proyecto memorial esperado desde hace años, que va más allá del exilio republicano y que permite presentar una radiografía de lo que ha sido el siglo XX a partir de la experiencia del internamiento y muy particularmente, como es obvio, teniendo en cuenta la historia de Francia. La lectura histórica que permite este recinto es realmente impactante. En enero de 1941, el gobierno de la Francia de Vichy abrió oficialmente las instalaciones del campo de Rivesaltes. En pocos días comenzaron a llegar los primeros internos procedentes de otros centros como Agde, Gurs o los campos de las playas del Rosellón. Muy pronto, el funcionamiento del campo se insiere en la lógica de exclusión de la Europa ocupada por el nazismo. Refugiados republicanos - que habían sido de los primeros en llegar y que se habían encargado de los preparativos de apertura del campo -, judíos extranjeros y gitanos son recluidos en el campo. La ruda climatología, la separación de las familias, la falta de higiene, las enfermedades son, juntamente con la falta de libertad, algunas de las muchas dificultades con las que deberán convivir los internos. Uno de los episodios más trágicos del campo de Rivesaltes fueron los envíos de hombres, mujeres y niños judíos hacia Auschwitz entre agosto y octubre de 1942.

Este nuevo memorial, cuyo edificio de nueva planta - obra del arquitecto Rudy Ricciotti dispone de 4000 metros cuadrados, presenta un enorme potencial formativo. Los tres ejes de esa fuerza pedagógica son la exposición permanente, el riguroso servicio educativo y el dinamismo de las actividades temporales. Concretamente, la exposición permanente, con una escenografía impactante en la que predomina el material audiovisual, plantea desde las consecuencias de la Guerra civil española hasta el proceso descolonizador de la Guerra de Argelia, pasando por los años difíciles de la Segunda Guerra Mundial y de la deportación a los campos nazis. Al mismo tiempo, la visita es una oportunidad única para 
conocer de primera mano la estructura espacial de un campo de internamiento, ya que este lugar tiene la particularidad de mantener, en estado ruinoso, una parte de los vestigios del campo.

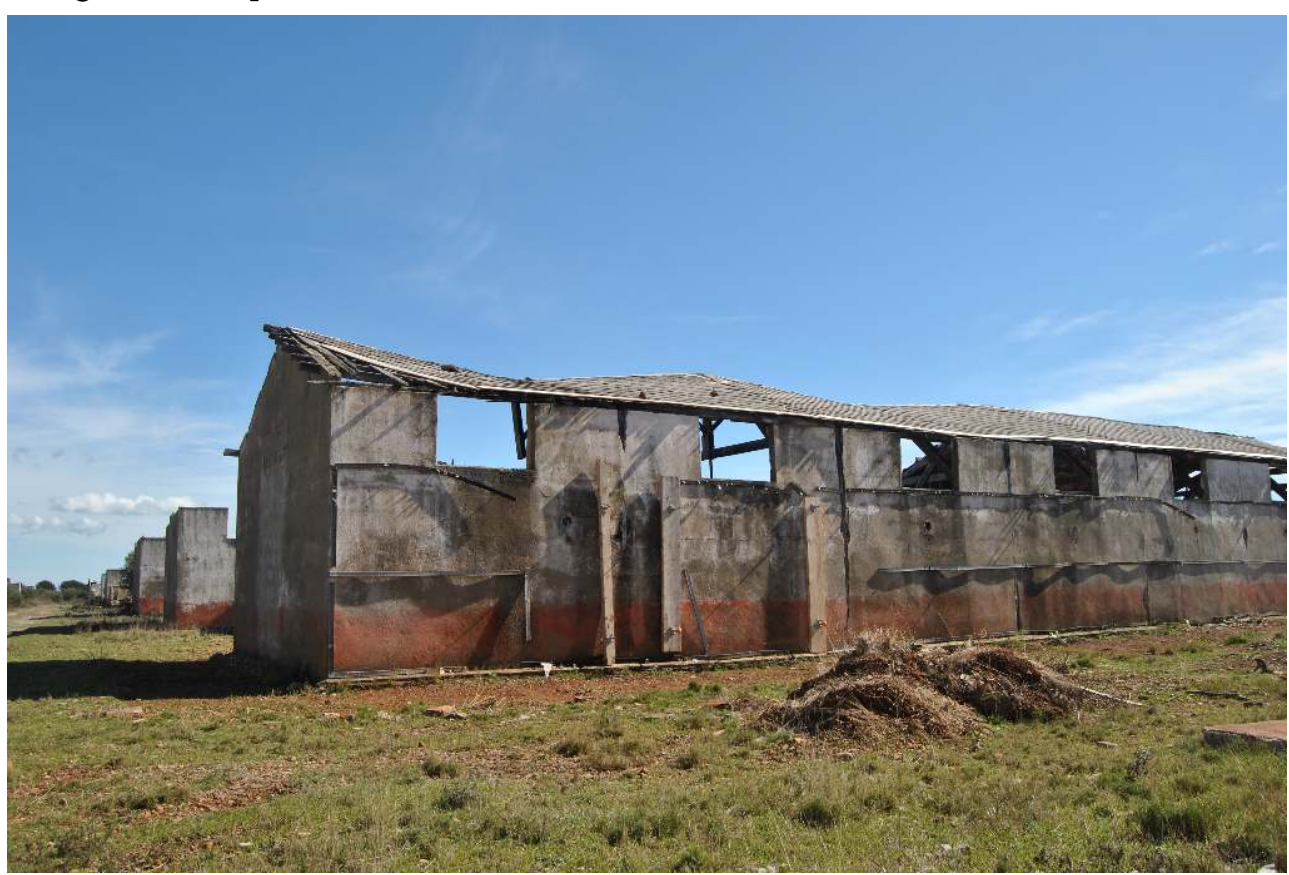

FIg. 5 - VESTIgIOS EXTERIORES, MEMORIAL DEL CAMPO DE RIVESALTES, 2014

(C) MUME

Tenemos pues, una zona transfronteriza en la que a partir de dos polos significativos y de referencia, el MUME y el recientemente inaugurado Memorial de Rivesaltes, se pueden articular unos nodos e itinerarios (Font 2014) capaces de tejer una realidad patrimonial y memorial de primer orden.

\section{Conclusiones}

Los lugares de memoria, diseminados a lo largo y ancho del continente europeo, en las décadas finales del siglo XX han sido protagonistas de un proceso de valorización patrimonial. Evocando aquellos hechos trágicos sufridos durante las dos guerras mundiales y el Holocausto, aunque ampliados también a la caída del muro de Berlín y la memoria de los totalitarismos soviéticos en el este de Europa, representan un importante testimonio destinado a perpetuar un sistema de valores relacionado con los derechos humanos y las libertades. En este sentido, la existencia de territorios transfronterizos representa el caldo de cultivo ideal para el desarrollo de una memoria colectiva a ambos lados de las antiguas fronteras, cuya finalidad no sea otra que la difusión de valores cívicos y éticos.

La Europa post-Schengen ha supuesto un acercamiento a nivel comercial entre las naciones del viejo continente, gracias al cual, podría decirse que también han podido estrecharse algunos lazos sociales y culturales. Dichos lazos, sin embargo, distan mucho de representar un elemento sólido, constante, y con posibilidad de recorrido. En aras de la consolidación de los mismos, son necesarias políticas públicas de memoria que promuevan la difusión de aquellos hechos históricos comunes entre vecinos antaño 
beligerantes. La creación de centros de interpretación, museos, y espacios de memoria museizados, está demostrando ser una herramienta extremadamente útil para consolidar la cicatrización de viejas pero crueles heridas, donde el ciudadano-visitante contemple el horror de forma crítica y no mediante un prisma de víctima ni de verdugo que pueda ser responsable de la perpetuación de memorias conflictivas y de confrontación.

El episodio histórico del exilio republicano de 1939, con sus numerosos espacios presentes en el territorio, representa un importante patrimonio común a ambos lados de la frontera pirenaica. Gracias al empuje inicial de las asociaciones de descendientes de exiliados, y a la posterior apuesta de diferentes entidades administrativas locales, dicho patrimonio se ha ido materializando en las diversas experiencias museísticas existentes en la actualidad, algunas de ellas expuestas en el presente artículo. Al sur de la antigua frontera, donde las circunstancias sociopolíticas dificultan aún más si cabe la puesta en valor de determinados patrimonios memoriales, la posibilidad de avanzar en la creación de elementos museísticos de la mano del país vecino supone una oportunidad para eliminar los tabúes ideológicos existentes todavía hoy en día. La dinámica actual parece avanzar en esa dirección, a la espera de la consolidación en un futuro próximo de todas las experiencias emprendidas recientemente.

\section{BIBLIOGRAFÍA}

Alessandrone Perona, Ersilia. 2005. "La Présentation de la Résistance et de la Déportation en Italie: Mémoires, Opinion, Politique à la Fin du XXè siècle.” En Musées de Guerre et Mémoriaux, dir. Jean-Yves Bousier, 113-123. Paris: Éditions de la Maison des Sciences de l'Homme.

Bernecker, Walther, Sören Brinkmann, y Marta Muñoz-Aunión. 2009. Memorias Divididas: Guerra Civil y Franquismo en la Sociedad y la Política Españolas 1936-2008. Madrid: Abada Editores.

Bouliou, Claude. 2013. “Du Tourisme des Batailles au Tourisme des Mémoires." Cahier Espaces 313: 68-71.

Calvet, Josep. 2008. Les Muntanyes de la Llibertat: El Pas d'Evadits pels Pirineus Durant la Segona Guerra Mundial 1939-1944. Barcelona: L’Avenç.

Camiade, Martine. 2010. “Territori, Paisatge i Exili. Rosselló 1939: Allò Viscut d’una Crisi Humanitària a partir de les Fonts Orals." En Reflexionant l'Exili: Aproximació a l'Exili Republicà: Entre la Historia, l'Art i el Testimoniatge, dir. Jordi Font, 49-62. Catarroja: Editorial Afers.

Cavaignac, François, y Hervé Deperne. 2003. "Les Chemins de Mémoire: Une Initiative de l'État." Cahier Espaces 80: 12-21.

Da Silva, Magali, y Laure Bougon. 2013. "Le Tourisme de Mémoire: Un Enjeu Civique, Pédagogique, Économique et Culturel pour la France.” Cahier Espaces 313: 48-51.

Font, Jordi. 2014. "Els Camins de l'Exili Republicà en la Història del Segle XX i la Preservació de la Seva Memòria: L'exemple del Museu Memorial de l'Exili (MUME). En L'Exili Republicà als Països Catalans: Una Diáspora Històrica, dir. Pelai Pagès, 73-108. Barcelona: Editorial Base.

Foucher, Michel. 1991. Fronts et Frontiers: Un Tour du Monde Géopolitique. Paris: Fayard. 
González, David. 2014. “Cap a Nous Models de Transmissió de Valors Democràtics: Catalunya i el Turisme de Memòria." Espais i Temps de Memòria. Revista Digital del Memorial Democràtic 2: 48-51.

Guixé, Jordi. 2008. “El Memorial Democrático y los Lugares de la Memoria: La Recuperación del Patrimonio Memorial en Cataluña." Entelequia 7: 217-228.

Huyssen, Andreas. 2002. En Busca del Futuro Perdido: Cultura y Memoria en Tiempos de Globalización. México: Fondo de Cultura Económica.

Lalieu, Olivier. 2003. “Mémoire de la Shoah: L'Action du Centre de Documentation Juive Contemporaine (CDJC). Cahier Espaces 80: 27-31.

Ley 55/2007, de 26 de Diciembre, por la que se reconocen y amplían derechos y se establecen medidas a favor de quienes padecieron persecución o violencia durante la guerra civil o la dictadura, BOE n.o 310, p. 53.410 (2007).

Llei 13/2007, del 31 d'octubre, del Memorial Democràtic, DOGC n.ำ 5006, p. 45.172 (2007).

Magris, Claudio. 2001. “Desde el Otro Lado: Consideraciones Fronterizas”. En Utopía y Desencanto: Historias, Esperanzas e Ilusiones de la Modernidad, ed. Claudio Magris, 55-70. Barcelona: Editorial Anagrama.

Mantei, Christian, dir. 2012. Le Tourisme de Mémoire en France: Mesure et Analyse du Poids et des Retombées Économiques et de la Filière. Paris: Atout France.

Ordre IRP/91/2010, de 18 de febrer, per la qual es crea la Xarxa d'Espais de Memòria Democràtica de Catalunya, DOGC n. ${ }^{\circ}$ 5576, p. 14651 (2010).

Pujol, Enric. 2008. “El Cas Català com a Paradigma." Mirmanda 3: 26-28.

Santacana, Joan, y Francesc Xavier Hernàndez. 2011. Museos de Historia: Entre la Taxidermia y el Nomadismo. Gijón: Ed. Trea.

Schlögel, Karl. 2007. En el Espacio Leemos el Tiempo: Sobre la Historia de la Civilización y Geopolítica. Madrid: Ediciones Siruela.

Urbain, Jean-Didier. 2003. “Tourisme de Mémoire: Un travail de Deuil Positif.” Cahier Espaces 80: 5-7.

Verkindt, Étienne, y Hélène Blanc. 2013. “Le 'Paysage de Mémoire': Un Concept en Construction.” Cahier Espaces 313: 80-87.

Vinyes, Ricard. 2009. “La Memoria del Estado”. En El Estado y la Memoria: Gobiernos y Ciudadanos Frente a los Traumas de la Historia, ed. Ricard Vinyes, 23-66. Barcelona: RBA Libros.

\section{RESÚMENES}

Los lugares transfronterizos europeos son espacios consolidados en la actualidad. Muchos de ellos han desarrollado dinámicas políticas, económicas y culturales, destinadas a asentar una identidad común más allá de los estados. En el ámbito cultural, se ha trabajado en la puesta en valor de aquellos patrimonios considerados comunes, y que sin duda ejercen como un fuerte nexo de unión entre los estados miembros de la UE. Los espacios de memoria ligados a los trágicos eventos bélicos de la Europa del siglo XX son uno de los principales patrimonios comunes a lo largo y ancho del continente, y su valorización se ha basado principalmente en la museización de los mismos, ya sea con la creación de nuevos museos y centros de interpretación, o ya sea con estrategias de museización sobre el territorio. La zona que denominamos el espacio catalán transfronterizo dispone de un importante patrimonio memorial ligado al exilio 
republicano ocurrido tras la Guerra Civil española. Con un abordaje metodológico basado en conjuntar análisis teórico con la propia experiencia sobre el territorio, este artículo muestra varias de las experiencias museísticas emprendidas alrededor de los espacios de memoria transfronterizos situados entre Cataluña y el extremo oriental del sur de Francia. Los ejemplos expuestos, algunos consolidados y otros más emergentes, nos muestran como una puesta en valor en clave museística puede colaborar decisivamente en la consolidación de una memoria compartida entre dos realidades estatales diferenciadas.

Cross-border sites in Europe are well established nowadays. Many of them have developed political, economic and cultural dynamics intended to secure a common identity beyond states. In the cultural sector, work has been undertaken on the enhancement of what is considered common heritage, which undoubtedly acts as a strong bond between European Union member states. The places of memory linked to the tragic war events in Europe during the $20^{\text {th }}$ century belong to the main common heritage throughout the continent and have been enhanced primarily by means of their museification, either by creating new museums and interpretation centres or by designing onsite museification strategies. The Catalan Cross-Border owns an important memorial heritage related to the Republican exile after the Spanish Civil War. Using a methodological approach based on the combination of theoretical analysis and onsite work, this article shows several museum experiences launched around the cross-border memorial sites located between Catalonia and southeast France. The examples shown, some well established and some emerging, teach us how a museum-related enhancement can contribute decisively to consolidate a shared memory between two different national realities.

\section{ÍNDICE}

Keywords: Spanish republican exile, Museo Memorial de l'Exili, memory, musealisation, cultural heritage

Palabras claves: exilio republicano español, Museo Memorial de l'Exili, memoria, patrimonio cultural, museización

\section{AUTORES}

\section{DAVID GONZÁLEZ VÁZQUEZ}

Es historiador, licenciado por la Universitat de Barcelona, máster en Turismo Cultural por la Universitat de Girona, y doctorando en Didáctica del Patrimonio, las Artes y el Turismo Cultural por la Universitat de Barcelona. Su especialidad y ámbito de estudio son los espacios de memoria ligados a la Guerra Civil, y más concretamente sus procesos de puesta en valor patrimonial. Trabaja en el servicio educativo del Museu Memorial de l'Exili (MUME) en La Jonquera, España, y es miembro de Memorias en Red-Asociación Internacional de Jóvenes Investigadores (MeR) y Grupo de Investigación en Didáctica del Patrimonio de la Universitat de Barcelona (DIDPatri). david.glez81@gmail.com

\section{JORDI FONT AGULLÓ}

Es historiador, licenciado por la Universitat Autònoma de Barcelona, gestor cultural y comisario de exposiciones. Especialista en arte actual, así como en historia sociocultural y las relaciones entre historia y memoria, ocupa el cargo de director del Museo Memorial de l'Exili (MUME) en La Jonquera, España. Es miembro de varios grupos de investigación sobre historia contemporánea y 
memoria en diversas universidades catalanas, como la Universitat Autònoma de Barcelona, la Universitat de Barcelona o la Universitat de Girona. Forma parte del Associació Catalana de Crítics d'Art (ACCA).gerencia@museuexili.cat 